\title{
LUDICIDADE NO ENSINO DA NORMALIDADE EM UM AMBIENTE FLORESTAL
}

\author{
Otacílio Antunes Santana \\ Universidade Federal de Pernambuco (UFPE), \\ Recife, Pernambuco, Brasil \\ Yekaterina Petrova \\ Universidade Estatal de Moscou (MSU), Moscou, Rússia
}

\begin{abstract}
RESUMO: A intenção desse trabalho foi aplicar a pedagogia explícita lúdica em um contexto florestal, a buscar a consolidação do conhecimento sobre o estudo da normalidade e a teia interdisciplinar que o conteúdo requer para sua compreensão. O jogo pré-determinado se baseou na amostragem de dados biométricos florestais por grupos de alunos do ensino médio, em que o primeiro grupo que atingisse a distribuição normal (D'Agostino K, 1970) no conjunto de dados coletados, ganhava a rodada. Alunos da licenciatura foram os supervisores e mediadores dos grupos. Após o planejamento, a interação lúdica e as avaliações, a vertente pedagógica utilizada mostrou ser um caminho para o engajamento motivacional e para a consolidação do conhecimento na teia interdisciplinar e transdisciplinar.
\end{abstract}

PALAVRAS-CHAVE: Pedagogia explícita. Jogo-problema. Alfabetização científica. Didática da Matemática.

INTRODUÇÃO

Os alunos matriculados, em sua maioria, em disciplinas que possuem em sua ementa tópicos de matemática e estatística, possuem certa ansiedade no início destas, a relatar um bloqueio ou uma dificuldade no aprendizado nessas áreas temáticas (MENDES; CARMO, 2014). Esse bloqueio pode ter sido 
autocriado em torno do'mito' dos relatos dos que já cursaram (e.g. notas baixas e dificuldade de compreensão), em torno dos métodos de ensino utilizados (e.g. muito cálculo teórico e pouca aplicação e contextualização), e em torno da dedicação exigida (tempo) em resolução de problemas e exercícios (ANGELO, 2012). Importante para isso, o docente na elaboração do plano de ensino e do percurso de aprendizagem, adotar estratégias distintas das clássicas, como a ludicidade, na qual a aplicação e teoria são lecionadas de forma síncrona e sem divisões temporais exatas entre elas, e que haja uma contextualização em um 'novo' ambiente (um cenário não formal) para que os alunos desmistifiquem e desbloqueiem preconcepções sobre a área temática em questão.

A intenção desse trabalho foi aplicar uma pedagogia que vá nessa direção, em termos de estratégias e possíveis mudanças de cenários. Para isso, foi utilizada a "pedagogia explícita lúdica" em um contexto florestal, a fim de buscar a consolidação do conhecimento sobre um conteúdo específico (estudo da normalidade), e a teia interdisciplinar que ele o requer para sua compreensão. Os conceitos, relevâncias e as justificativas serão apresentadas na sequência do texto, mas para guiar a leitura dos referenciais teóricos, os objetivos desse trabalho foram: i) ludicizar o ensino da normalidade no ensino médio, mediado por alunos de licenciatura, e ii) analisar os processos de interação, consolidação e avalição aplicados.

Os alunos de ensino médio foram escolhidos como participantes desse trabalho por terem em seus currículos o conteúdo trabalhado (normalidade) e pela habilidade requerida em seu estádio de desenvolvimento (operatório formal) "recém ingressado", de raciocínio lógico, sistemático e proposicional, de deduções lógicas e pensamento hipotético-dedutivo, de aprender a criar conceitos e ideias sem o apoio de objetos concretos, e de planejar ações coletivas (PIAGET, 2002). E tudo isso sintetiza as bases do pensamento científico. A escolha dos alunos de licenciatura para mediarem e supervisionarem o jogo foi devido ao contato já estabelecido com os alunos de ensino médio (Regências nos Estágios de Ensino), e pela sua formação docente exigir a vivência em pedagogias de distintas estratégias de ensino e diferentes formatos de avaliação. Uma situação em que os alunos de licenciatura e alunos de ensino médio possam de forma dinâmica construir e consolidar o conhecimento, na qual cada sujeito traga de forma significativa seu conhecimento, sua experiência e sua sensibilidade, é relevante no processo de ensino e aprendizagem.

A "Pedagogia Explícita" foca dentro do processo de consolidação do conhecimento, nas meta-análises e nos estudos longitudinais de cooperação aluno-aluno e docente-aluno (GAUTHIER et al., 2013). O planejamento é guiado 
pelas experiências já percorridas, porém na sua execução, o onto pedagógico toma rumos próprios. Esse percurso pedagógico é um processo dinâmico e cíclico, em que não se separa teoria e prática (GAUTHIER; TARDIF, 1996). Os elementos fundamentais a serem dinamizados para esse percurso são: o cenário; as premissas e pré-requisitos; os modelos a serem desconstruídos; as práticas guiadas; as práticas independentes; a objetivação e subjetivação; e a síntese. Esses elementos se fundem para privilegiar as diversas cargas cognitivas dos sujeitos em aprendizagem. Há aqui então a união da teoria de redes semânticas (a significação no contexto) e da teoria da carga cognitiva (o que cada aluno acrescenta para a construção do conhecimento), a fortalecer na práxis a memória de curto prazo e a memória semântica de longo prazo (GAUTHIER et al., 1997).

A ludicidade se encaixa perfeitamente na pedagogia explícita, pois, com a execução do lúdico, teoria e prática são refletidas simultaneamente, o cenário (espaço/tempo), as regras, os jogadores (sujeitos), a situação, e a incerteza quanto ao resultado, permitem na práxis (interação) a consolidação do conhecimento (CAILLOIS; BARASH, 1961; MUNIZ, 2010). Outros elementos como liberdade e improdutividade, inerentes ao jogo, são elementos da subjetivação e do foco no processo que a pedagogia explícita ressalta (CAILLOIS, 2015). Além da inserção do lúdico na dinâmica pedagógica, as avaliações como parte do processo de consolidação e do Feedback de toda interação, fecha o ciclo da pedagogia explícita lúdica (Figura 1) (Gauthier et al., 2013). O planejamento das turmas futuras se dará pela análise e reflexão sobre o Feedback.

Figura 1 - Processo da Pedagogia Explícita Lúdica.

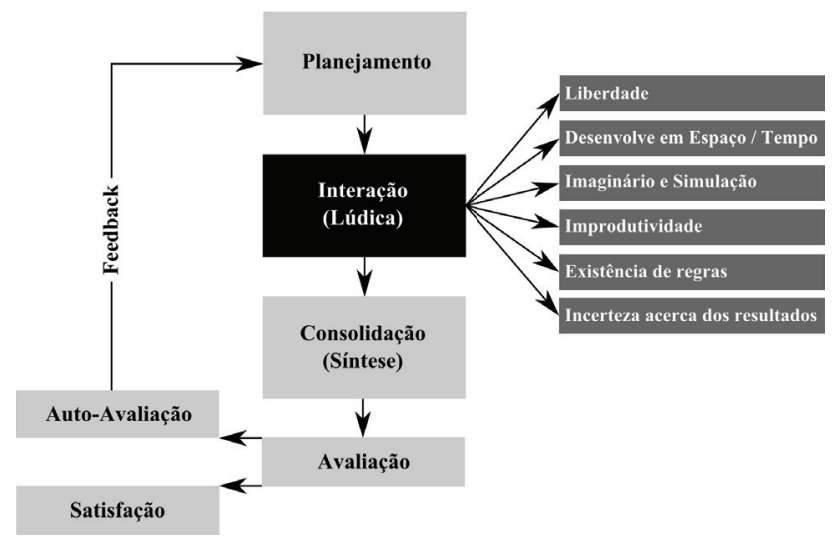

Fonte: Adaptado de Gauthier et al. (2013) e Caillois (2015). 
A fragmentação do conhecimento deixou alguns conhecimentos estáticos e isolados (MORIN, 1990). Como é o caso da Matemática, da Estatística e das Ciências Naturais, que da maneira tecnicista que são ensinadas, os alunos interpretam como se o conhecimento já tivesse atingido um fim, está pronto e acabado (D'AMBRÓSIO, 1996). Quando se leciona uma teoria e depois se aplica à prática, o docente certifica isso. Pensar a proposta dos Parâmetros Curriculares Nacionais é interagir as disciplinas (interdisciplinaridade) e explicitar o caráter dinâmico e inacabado do conhecimento (BRASIL, 2000). Alguns autores defendem a transdisciplinaridade, que vai além das disciplinas e da capacidade de que cada uma tem de se modificar frente à temática a ser lecionada (MACHADO; DAMBROSIO, 2014). Nesse contexto, a pedagogia explícita lúdica 'desfragmenta' as áreas temáticas e pensa o problema sob a ótica de todas as ciências possíveis (exatas, humanidades e artes).

A aplicação de métricas à natureza e o entendimento do sistema natural é clássica (Biometria) (SOKAL; ROHLF, 1995). A busca de padrões naturais (quantitativos) e a explicação do dado fora dos padrões (qualitativos: evidências) são métodos utilizados por pesquisadores e deveriam ser empregados no processo de ensino e aprendizagem interdisciplinar (SANTANA, 2014). Essa epistemologia pedagógica se aplica à pedagogia explícita lúdica no ensinar interdisciplinar sensível, que é a partir dos números, mas para além deles.

\section{O Jogo da Normalidade}

O Jogo da Normalidade se objetiva na busca da significância da distribuição dos dados frente à distribuição normal, ou seja, a partir de qual $n$ amostral o conjunto dos dados estará distribuído de forma normal. Basicamente, esse tipo de distribuição de dados é quando, em uma amostragem, a maior frequência dos registros dos dados estiver sob a média dos resultados, ou a maior probabilidade do resultado de um novo dado registrado ser sobre a classe de maior ocorrência (ZAR, 1999).

A normalidade adotada para esse jogo é o Teste de D'Agostino $\left(\mathrm{K}^{2}\right)$, indicado para dados florestais pela tendência dos dados se distribuírem de maneira normal e simétrica de seus desvios padrões (premissa 1), pela suficiência amostral se caracterizar pela normalidade dos dados (premissa 2), tudo isso em uma amostragem aleatória (premissa 3) (D'AGOSTINO, 1970; D'AGOSTINO; PEARSON, 1973; D'AGOSTINO; BELANGER; D'AGOSTINO JR, 1990). O teste de $D^{\prime} A g o s t i n o ~\left(K^{2}\right)$ se baseia no cálculo de $K^{2}$ para posterior 
determinação de $p$ (valor da significância). O K² é um teste de aderência, calculado a partir da aproximação da curva dos dados coletados à curva da distribuição normal teórica, com os parâmetros de simetria dos desvios padrão (da curva) e curtose (achatamento ou alongamento da curva). $O p$ significa a probabilidade de um dado, ou de seu conjunto, ocorrer dentro da classe esperada na curva normal, ou seja, quando o valor de $p$ for igual a 1 , significa que o conjunto de dados se encaixou perfeitamente à distribuição normal, tanto na frequência sob a média como nos desvios padrões. A hipótese nula $\left(H_{0}\right)$ guiará a normalidade, quando o valor de $p$ for $\geq 0,05(95 \%$ de confiança), será o momento em que a distribuição dos dados chegará a Normal (D'AGOSTINO; BELANGER; D'AGOSTINO JR, 1990).

As regras do jogo são: i) mensurar no primeiro momento o dap (diâmetro a altura do peito do tronco) das árvores de forma aleatória no talhão, e no segundo momento a h (altura) (Figura 2); ii) cada árvore amostrada é marcada (com fita colorida); iii) simultaneamente à coleta dos dados, uma planilha eletrônica é fomentada em um dispositivo móvel (celular ou tablet) com cada dado registrado, e, instantaneamente, é determinado o valor da significância ( $p$ ) do teste; iv) a cada rodada do jogo apenas dois grupos se confrontaram; e v) a equipe que primeiro atingir o $p \geq 0,05$, anuncia ao supervisor e ganha a rodada, até sobrar duas equipes e uma for a vencedora.

A importância desse jogo é que ele dinamiza a consolidação do conhecimento em um espaço não formal (ambiente). Os sujeitos envolvidos estarão em constantes situações-problema (e.g. que árvore medir para chegar logo à significância), em contato com um ambiente "desconhecido" (e.g. onde pisar), e sob uma linha do tempo que urge. Esses três fatores mencionados instigam a criação de hipóteses e a tomada de decisões rápidas. O jogo é de base competitiva (entre os grupos), porém, para a execução das tarefas e das soluções frente ao desafio, tudo isso de forma eficiente, faz com que o grupo defina funções e papéis em seu coletivo (cooperação) para que atinjam essa eficiência em relação ao grupo concorrente. Além dos objetivos educacionais, o fato dos sujeitos estarem envolvidos sob o lúdico pode erradicar pré-concepções sob a área temática (e.g. métodos clássicos), motivar os alunos e os mediadores, e conectar a aprendizagem de um conteúdo algo prazeroso (MUNIZ, 2010).

Para os mediadores, as situações, e como os alunos as superaram, são registros empíricos e científicos da avaliação holística da atividade curricular (educação como processo) relevantes para sua sistematização e divulgação. As avaliações e os feedbacks em relação ao jogo servirão de bases primárias para o planejamento curricular de novas turmas e novos cursos (D'AMBRÓSIO, 1996). 


\section{Metodologia}

O cenário utilizado foi um ambiente florestal, ambiente com estímulos sensoriais propícios para a construção de hipóteses individuais e coletivas, e para a sintetização de respostas entre os alunos mediados pelo docente, com os objetos de aprendizagem necessários (SANTANA; IMAÑA-ENCINAS, 2013). A floresta de Eucalyptus urophylla S. T. Blake (Myrtaceae), situada a $13^{\circ} 54^{\prime} \mathrm{S}$ e $46^{\circ} 15^{\prime} \mathrm{O}$, foi delimitada em talhões florestais de $4.104 \mathrm{~m}^{2}$, com indivíduos arbóreos (aproximadamente 35 anos de idade) espaçados a $3 \mathrm{~m} \times 3 \mathrm{~m}$, a formar um retângulo de 25 por 20 indivíduos (total 500 árvores) (Figura 2A). As variáveis mensuradas foram o dap = diâmetro da árvore à altura do peito (a 1,30 $\mathrm{m}$ de altura), medido com uma suta (paquímetro); e $\mathrm{h}=$ altura total da árvore (Figura 2B), medida com um Hipsômetro Vertex IV (Haglöf, Suécia).

Figura 2 - A) Talhão Florestal; e B) Variáveis biométricas amostradas (dap = diâmetro à altura do peito e $\mathrm{h}=$ altura)



Fonte: Elaborado pelos autores.

Os jogadores foram alunos do ensino médio (terceira série) de escolas públicas pernambucanas, divididos em grupos com aproximadamente dez alunos cada. Seis escolas participaram com um total de 317 alunos (32 grupos). As escolas escolhidas fazem parte de programas de Estágios em Ensino de Matemática, Estatística, Física, Biologia e Química, estágios curriculares para os cursos de Licenciatura das Universidades Federais em Recife (Universidade Federal de Pernambuco - UFPE e Universidade Federal 
Rural de Pernambuco - UFRPE). O grupo amostral foi definido pela adesão dos alunos à pesquisa e sua participação nas regências dos licenciandos. Todos os quesitos éticos foram seguidos conforme a legislação vigente (BRASIL, 2012). Foram mensurados 32 talhões distintos. Os grupos foram supervisionados individualmente por alunos de Licenciatura matriculados nos Estágios referidos anteriormente.

As primeiras análises do jogo foram a análise gráfica gerada pelos grupos e a discussão dos alunos do ensino médio após a coleta dos dados. Posteriormente foi realizada a análise das avaliações: de conteúdo, a autoavaliação e a satisfação de participação do jogo. As avaliações foram realizadas em dois momentos: um antes da aplicação da pedagogia explícita lúdica e outra após. Antes da aplicação da vertente pedagógica proposta, o ensino foi baseado em aulas expositivas e práticas de resolução de exercícios em sala de aula. O teste estatístico Qui-Quadrado $\left(X^{2}\right)$ foi executado entre os momentos (antes e depois) para verificação de diferenças significativas (ZAR, 1999). E por final, a análise da discussão dos alunos de ensino médio e dos licenciandos a observar as análises gráficas e as avaliações.

O formato das avaliações de conteúdo foi um exame de cinco questões sobre exercícios interdisciplinares aplicados de forma individual e, logo após, seminários ( $\pm 20 \mathrm{~min}$ ) em grupos de cinco indivíduos (de forma coletiva). Os critérios dos seminários foram quanto a: i) organização lógica e temporal do tema; ii) aplicação e contextualização; iii) didática e diálogo com a turma; iv) criticidade (sobre o tema ou sobre a condução do tema pela mídia e sociedade); e v) proposta de inovação. Cada avaliação com valor de cinco: exame + seminários $=$ dez.

A autoavaliação sobre a participação do aluno na disciplina foi respondida na medida em que se davam a cada item uma nota de zero a dez (escala LIKERT, 1932), sendo que zero não houve uma dedicação satisfatória por parte do aluno no critério de autoavaliação, e dez, houve uma dedicação totalmente satisfatória no critério. Os critérios da autoavaliação se basearam na perspectiva de que o aluno agisse com (SITZMANN et al., 2010): i) autodisciplina (cumpriu com o solicitado pelo mediador); ii) autonomia (pró-ativo); iii) autodidatismo (criou e/ou sistematizou seus métodos de aprendizagem); iv) interação com a turma; v) cooperação com os colegas; vi) diálogo em busca da síntese (e.g. respeitou as divergências de pensamento, de métodos, de ideologias, etc.); vii) inovação (rompeu com o tradicional e com o método hegemonicamente dominante); e viii) superação (estudou além do solicitado no currículo). 
A satisfação na participação do jogo também foi parametrizada pela escala Likert (1932), em que zero significa "pouco satisfeito" e dez"muito satisfeito". Os resultados quantitativos da avaliação, autoavaliação e satisfação foram analisados e validados pelas discussões e evidências qualitativas postas pelos alunos do ensino médio e de licenciatura no momento de discussão pós-avaliações. As variações dos resultados por aluno foram apresentadas na forma gráfica denominada de box-plot (ZAR, 1999).

As discussões com os alunos, e a posteriori, com os licenciandos, foram gravadas e analisadas após descrição, segundo a frequência das palavras (nuvem de palavras) das principais démarches (BILLOUET, 2007) que ajudaram na convergência das narrativas (GANCHO, 1991) sobre o sucesso ou insucesso no processo da pedagogia explícita lúdica. As nuvens de palavras (tag clouds) foram geradas com o auxílio do aplicativo WordleTM (SANTANA, 2016a, b).

\section{ANÁLISES E DisCusSÕES}

Os resultados apresentados pelos alunos atingiram o objetivo da proposta do jogo: chegar à normalidade e consequentemente à suficiência amostral (Figura 3). Os valores de $p$ se tornaram 0,05 próximos entre os taIhões. Em uma disputa entre dois talhões, o $n$ amostral que torna o conjunto de dados em distribuição normal foi de 231 em um, e 259 em outro, para variável dap (Figura $3 \mathrm{~A}$ e $3 \mathrm{~B}$ ). A análise gráfica permitiu a visualização da dinâmica dos dados frente a uma significância $\left(K^{2}\right.$ e $\left.p\right)$ e uma tendência natural. Além de um simples dado estatístico, o padrão natural foi observado e junto dele algumas exceções, importantes na convergência e divergência das discussões no ensino das ciências (BIZZO; CHASSOT, 2013). Essa construção gráfica é relevante, pois "todo conhecimento é inseparável dos fenômenos de representação" (DUVAL, 1995).

Dessa forma, alguns questionamentos surgiram aqui: i) Toda a natureza segue um padrão estatístico?; ii) As exceções são anormalidades?; iii) Esse $n$ da suficiência amostral (ponto de inflexão significativa) não é fixo para todos os talhões?; iv) Os talhões formados por clones de indivíduos (geneticamente iguais) não deveriam ser iguais?; v) Qual a influência de outras variáveis do fenótipo (e.g. pluviosidade) em indivíduos de mesmo genótipo?; vi) Os momentos de significância entre as variáveis (n) são distintos (e.g. dap n entre 211 e 262; e h n entre 307 e 362)?; entre outros. Esses questionamentos suscitaram o caráter interdisciplinar que aflorou na elaboração dos gráficos, 
perguntas da estatística (e.g. questionamento iii), a biologia (e.g. questionamento v), a filosofia (e.g. questionamento i), e outras. Nesse momento, os questionamentos emergidos transformam a temática e a fazem caminhar na teia complexa do conhecimento (transdisciplinaridade) (D'AMBRÓSIO, 1996; MACHADO; DAMBROSIO, 2014).

Figura 3 - Resultado da amostragem de uma rodada entre dois grupos de alunos para diâmetro à altura do peito $=$ dap $(\mathrm{A}$ e B $)$ e altura $=\mathrm{h}(\mathrm{C}$ e D). Valor do $p$ do Teste de Normalidade D'Agostino $\left(\mathrm{K}^{2}\right)$
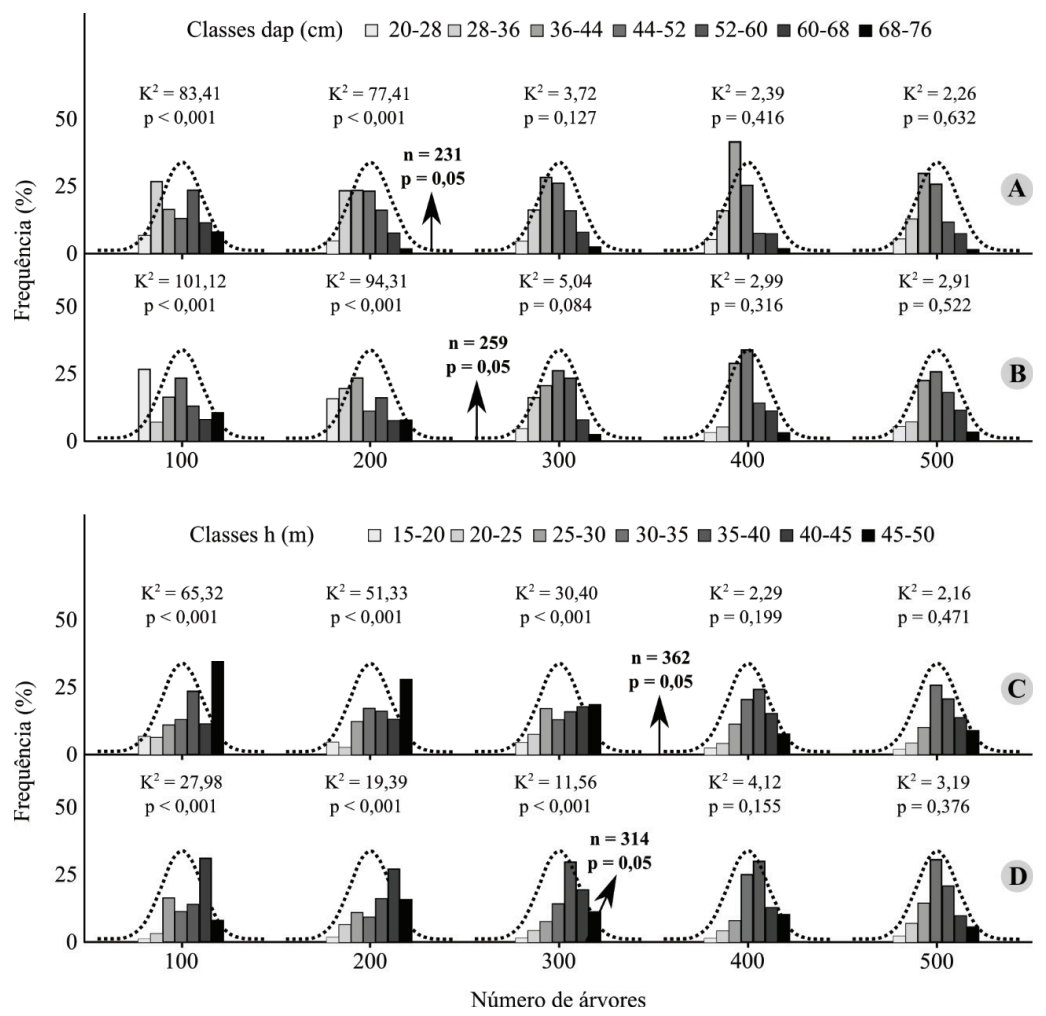

Fonte: Elaborado pelos autores.

Além das percepções teóricas, com os questionamentos emergidos, as questões práticas metodológicas também emergiram. Porque se mede a altura do peito? Se estiver ventando, eu espero as folhas ficarem imóveis? Meço até a altura da última folha ou do último galho? Se coletarmos os 
dados em zigue zague terá outro resultado? Se coletarmos aleatoriamente por diversas vezes, daria o mesmo resultado? E se fosse na Caatinga ou na Mata Atlântica? A questão da situação do problema com o pensamento no espaço/tempo determinado (contexto), fez com que os alunos começassem a pensar o processo em si a partir do produto (o resultado estatístico). E isso é o ponto chave para a pedagogia explícita lúdica, no momento em que o aluno imagina e simula a situação através da incerteza dos produtos em outros cenários (APPY; APPY, 2015).

Outros pontos de destaque foram as 'saídas' (soluções) encontradas in loco no momento da coleta dos dados. Como se organizariam e cooperariam no grupo?, Qual a melhor maneira de ganhar tempo na coleta de dados (eficiência) e ter um dado preciso (efetividade)?, Como andar no meio do ambiente florestal?, Como se livrar de insetos?, Como acrescentar simultaneamente os dados ao dispositivo móvel e analisar os resultados? etc. As dificuldades iniciais foram superadas a partir de cada coleta, ou seja, quanto mais se aproximavam do $n$ amostral significativo, mais eficientes e efetivos foram na coleta dos dados, e mais questionamentos foram surgindo e sendo erradicados (insights): objetivo da pedagogia explícita lúdica (GAUTHIER et al., 2013; CAILLOIS, 2015). Essa ação se assemelha ao processo de progressivas tentativas no confronto com um problema, na qual os sucessivos erros levam à aproximação da eureca (tâtonnement), à criação de um procedimento científico no jogo-problema (CAMOUS, 1985).

Os resultados das avaliações reforçaram que a pedagogia explícita

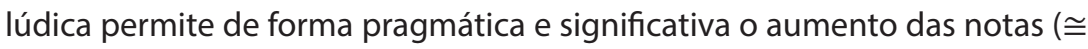
$30 \%$ ), refletidas no aumento do resultado da autoavaliação e na satisfação do processo de consolidação do conhecimento ( $p<0,001$, Figura 4). Com a pedagogia explícita lúdica no resultado da avaliação de conteúdo, os alunos passaram de uma média de 5,0 $( \pm 2,1)$ para 8,6 $( \pm 1,3)$. Isso também aconteceu devido ao cumprimento dos critérios dos seminários, em que a maioria dos grupos tirou cinco $(5,0 / 5,0)$. A organização lógica e temporal do tema, sua aplicação e contextualização, a didática e o diálogo com a turma, a criticidade, e as propostas de inovação apresentadas, mostraram a maturidade dos alunos em relação ao conteúdo discutido. No individual, os erros em sua maioria foram em cima do produto final (resultado de $\mathrm{K}^{2}$ ou $p$ ) e não do processo de construção do resultado ( $100 \%$ de acerto).

Os resultados da autoavaliação passaram de uma média de $6,9( \pm 2,3)$ para $8,8( \pm 0,4)$. Com o lúdico, os valores dos critérios de interesse pessoal aumentaram aproximadamente $28 \%$ em autodisciplina, autonomia, autodi- 


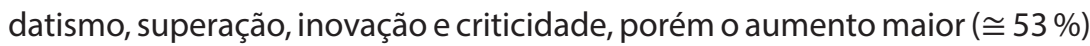
foi nos quesitos de coletividade: interação, cooperação e diálogo com a turma, critérios importantes para a construção do conhecimento (VYGOTSKY, 1989; PIAGET, 2002). E o lúdico, juntamente com a proposta pedagógica, proporcionou uma maior satisfação, em média $9,6( \pm 0,9)$ do que antes $(5,9 \pm 1,1)$. A corroborar com esse pragmatismo das notas quantitativas, as nuvens de palavras formadas pelas narrativas dos alunos e dos licenciandos ressaltaram a percepção do processo lúdico frente a processos de ensinagem anteriores (Figura 5 e 6). Esse pragmatismo não é a principal e nem a única forma de avaliar o processo, mas é basilar (DEWEY, 1938).

Figura 4 - Resultados das avaliações $(n=317) .{ }^{*} p<0,001$ do Teste $\chi^{2}$

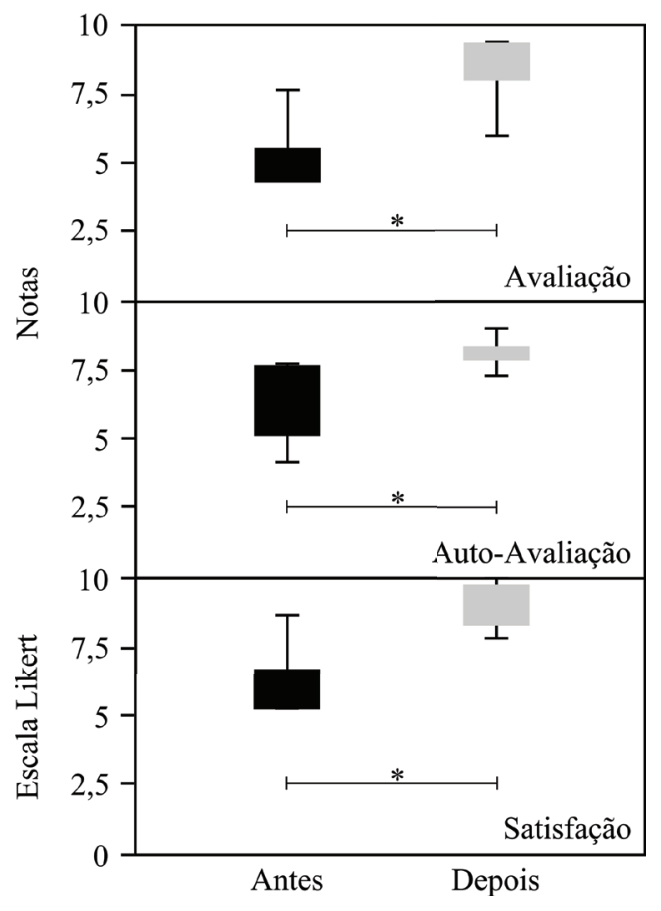

Fonte: Elaborado pelos autores.

Os alunos do ensino médio se sentiram motivados com o brincar em um cenário/situação novos (espaço não formal) e estimulados com a interação cooperativa/competitiva para a busca de um resultado incerto (Figura 5). 
A simples modificação do cenário e dos objetos educacionais no processo educativo gerou um potencial favorável para a consolidação do conhecimento (ERAUT, 2000). Os licenciandos registraram também a motivação apresentada pelos alunos e por eles próprios em aplicar uma atividade de ensinagem lúdica e brincante (Figura 6). Os alunos que demonstraram alguma insatisfação ( $n=$ 2; notas mais baixas na satisfação $<8$ ) foram aqueles que por algum motivo não estavam habituados a frequentar ambientes bucólicos, mudar a rotina, ou por algum motivo tinham alguma limitação física, ou limitação para executar uma atividade cognitiva e física simultaneamente, tudo isso sobre o olhar do "outro" (colega). Esse comportamento já foi descrito pela literatura (ANDA et al., 2000), que alguns alunos ou por timidez e introspecção, ou com medo de sofrerem bullying, ou mesmo por alguma exposição, ou por um comportamento antissocial inerente, preferem ser 'invisíveis' em sala de aula, não serem notados, e que atividades extraclasse, lúdicas, dinâmicas, seminários e outras atividades que os exponha (zona de estresse), não contribuem para seu aprendizado. Nesses casos, o baixo rendimento nas avaliações gerais não é culpa do aluno, pois em avaliações individuais, em geral, obtém notas elevadas $(>7,0)$.

Figura 5 - Nuvem de palavras formada a partir da discussão com os alunos do ensino médio sobre a atividade lúdica proposta

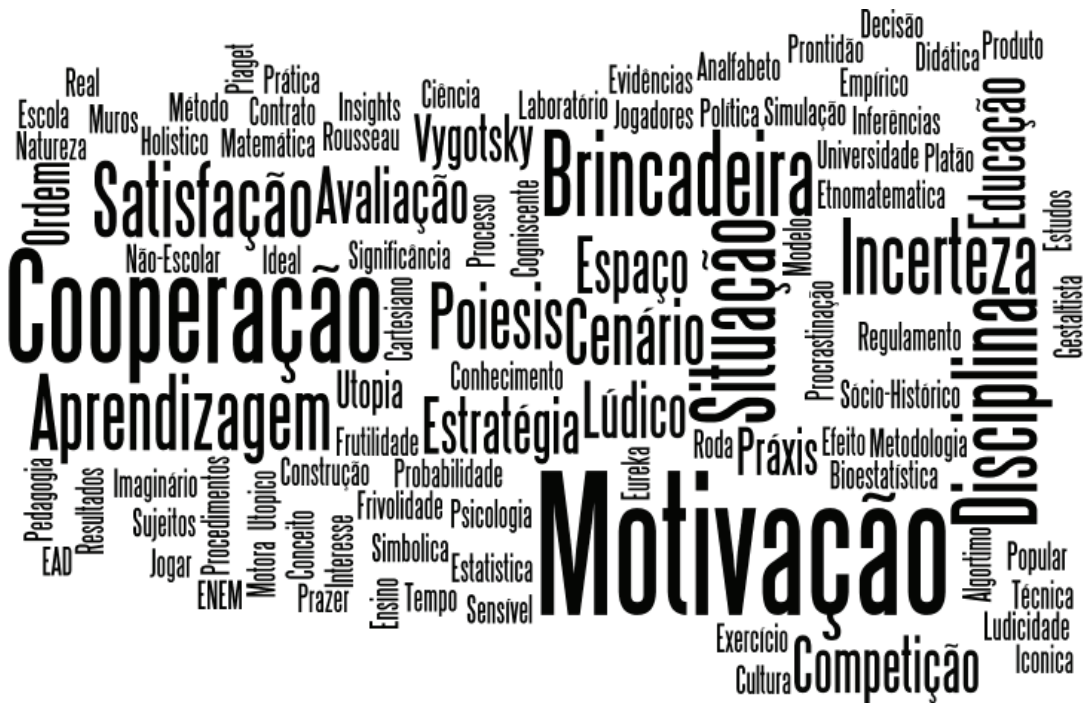

Fonte: Elaborado pelos autores. 
Figura 6 - Nuvem de palavras formada a partir da discussão com os licenciandos sobre a atividade lúdica proposta

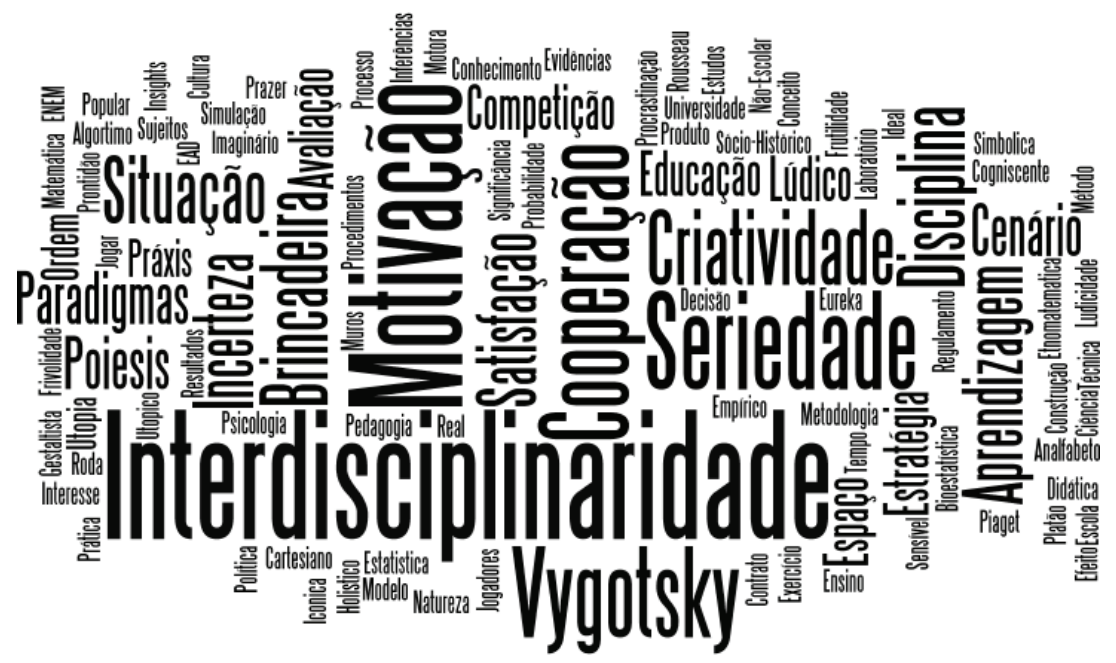

Fonte: Elaborado pelos autores.

O destaque principal dos licenciandos foi a interdisciplinaridade da atividade, o contato com o ambiente (o rústico), as saídas para os problemas (na coleta dos dados), o cálculo automatizado, a incerteza do resultado, a filosofia do "padrão" da natureza, entre outros. Outro tópico ressaltado foi a "seriedade" com que o grupo se engajou à "causa" (ganhar o jogo) de forma cooperativa, em que todos participaram e tiveram uma função definida, o que pouco ocorre com "trabalhos em grupo" nos espaços formais escolares, em que no grupo, um ou dois alunos fazem o trabalho e tomam a decisão por vários (ERAUT, 2000; KRASILCHIK, 2004).

A criatividade também foi um ponto destacado pelos supervisores (alunos de licenciatura). Ao longo da coleta dos dados, os alunos perceberam que algumas árvores mais finas (com baixos dap), ou mais grossas (com altos dap), aproximavam o $p$ da significância desejada, ou seja, escolhiam e tinham convicção de selecionar qual árvore seria a próxima a ser mensurada (perceptibilidade). Outro destaque foi a identificação da atividade com o pensamento de um autor: Lev Semionovitch Vygotsky. Os licenciandos associaram o ambiente (cenário e objetos educacionais dados) e as interações aluno-aluno com os marcos teóricos sistematizados por Vygotsky 
(1989; 2001): a) mediação, pelos licenciandos; b) processo de internalização do comportamento, pelo contato com outros alunos e professores; c) zona de desenvolvimento proximal iminente, em que a diversidade de níveis de conhecimento individual ajuda em sua construção coletiva, ou seja, os com o conhecimento mais consolidados auxiliam os que ainda estão em processo de construção; d) formação de conceitos, o confronto de conceitos dados (livros) com os conceitos gerados espontaneamente na ação (práxis); e) significado e sentido, em que os símbolos da matemática e estatística representam a natureza e suas informações (interação entre linguagem e pensamento). Aspectos teóricos complementares já mencionados, associaram a obra de Vygotsky $(1989 ; 2001)$ à práxis educativa matemática e natural, como a criatividade, conteúdos e desenvolvimento cognitivo (resolução de problemas), atividade e consciência, e atividade compartilhada (MOYSÉS, 2009).

Apesar da pedagogia socioconstrutivista de Vygotsky centralizar a pesquisa no aluno em um contexto de desenvolvimento sociocultural, e a pedagogia explícita focalizar na interação no momento do processo (o imprevisível), elas possuem muitas convergências, conforme já explicitado. $O$ importante é que o lúdico, como espaço e tempo potenciais, costura e supera os contextos, o aluno consegue consolidar e trabalhar na interface daquilo que é objetivamente percebido e daquilo que é subjetivamente concebido (WINNICOTT, 1975), e isso ficou evidenciado com o jogo proposto, com as análises e os questionamentos emergidos nesse trabalho.

\section{Considerações Finals}

O Lúdico é uma estratégia relevante no processo de ensino e aprendizagem, pois teoria e prática são refletidas simultaneamente, e proporciona uma dinâmica pela mudança do cenário da sala de aula, pelo agir sob as regras do jogo, pelos jogadores como sujeitos da ação e modificadores dela, pela "nova" situação-problema, pela incerteza quanto ao resultado, pela liberdade de caminhos e pela improdutividade (foco no processo). Essa ludicidade inserida na pedagogia explícita para o ensino da normalidade em um ambiente florestal se mostrou um caminho para um engajamento motivacional e para consolidação do conhecimento na teia interdisciplinar (matemática, estatística e ciências naturais) e para além (transdisciplinaridade), com o grupo amostral conduzido (alunos do ensino médio). 
Os próprios supervisores e mediadores (alunos da licenciatura) perceberam a motivação, a seriedade, a cooperação, o sucesso, as incertezas e o contexto que o jogo trouxe. Tudo isso potencializado nas avaliações e evidenciado nas narrativas, aumentando seus valores de maneira significativa em relação ao período anterior à aplicação da pedagogia explícita lúdica. A interação coletiva do jogo no ambiente criou uma zona de desenvolvimento proximal, na qual os alunos de ensino médio se ajudaram na solução de problemas, na construção do conhecimento, com a mediação dos alunos de licenciatura. A imprevisibilidade do que ocorre no processo em si, e a busca de soluções a cada etapa do jogo, corroboraram com a literatura do ensino das ciências naturais e matemáticas, e toda investigação associada, das pedagogias que primam pela "alfabetização científica" dos alunos e dos mediadores, devem investir no processo (no caminho) e pouco no produto em si.

Para o grupo e a situação amostral analisados nesse trabalho, e os objetivos de ludicizar o ensino da normalidade no ensino médio, conduzido por alunos de licenciatura, e analisar o processo de interação, consolidação e avalição aplicados, o jogo, as meta-análises e sua representação final, foram um percurso favorável para a consolidação do conhecimento. $O$ caminho futuro é aplicar a pedagogia explícita lúdica em distintos cenários, com outras variáveis e outros conteúdos. Outros testes estatísticos e funções matemáticas poderão ser utilizados no lugar da normalidade. E a contribuição dessa pesquisa às ciências da educação é o foco nas meta-análises e nos meta-métodos, e como ainda se pode sistematizar no campo lúdico as práxis que constroem e consolidam o conhecimento.

\section{AgradeCIMENTOS}

Ao grupo de pesquisa "Educometria" (CNPq/UFPE) pela discussão e análise dos dados. A Pró-Reitoria de Extensão e Cultura (PROExC) e a Pró-Reitoria para Assuntos de Pesquisa e Pós-Graduação (PROPESQ) da Universidade Federal de Pernambuco, pelo apoio financeiro. 


\section{PLAYFULNESS IN NORMALITY TEACHING IN A FOREST ENVIRONMENT}

ABSTRACT: The purpose of this work was to apply the explicit pedagogy with playful learning in a forest context to seek consolidation of knowledge about the study of normality and the interdisciplinary net that the content requires for its comprehension. The predetermined game was based on sampling of forest biometrics variables, by secondary student groups, where the first group that reached the normal distribution (D'Agostino K 1970) in the collected data set would win the round. Licentiate undergraduate students were supervisors and mediators of groups. After planning, the playful interaction and evaluations, the educational action used proved to be a path to motivational engagement and consolidation of knowledge in interdisciplinary and transdisciplinary net.

KEYWORDs: Explicit Pedagogy. Game-Problem. Scientific Literacy. Didactics of Mathematics.

\section{LO LÚDICO EN LA ENSEÑANZA DE LA NORMALIDAD EN UN AMBIENTE FORESTAL}

RESUMEN: El propósito de este trabajo es aplicar la pedagogía explícita lúdica en un contexto forestal para buscar la consolidación de conocimientos sobre el estudio de la normalidad, y la red interdisciplinar que el contenido requiere para su comprensión. El juego predeterminado se basó en un muestreo de datos biométricos en forestas por grupos de estudiantes secundarios, en el que el primer grupo que llegue a la distribución normal (D’Agostino K, 1970) en el conjunto de datos recogidos, ganaba la rueda. Estudiantes del curso de formación para el profesorado eran los supervisores y mediadores de grupos. Después de la planificación, la interacción lúdica y las evaluaciones, la acción educativa utilizada resultó ser un camino para mantener la motivación y consolidar el conocimiento en la red interdisciplinaria y transdisciplinaria.

PalABRAs-clave: Pedagogía explícita. Juego-problema. Alfabetización científica. Didáctica de Matemáticas.

\section{REFERÊNCIAS}

ANDA, D. et al. Stress, stressors and coping among high school students. Children and youth services review, v. 22, n. 6, p. 441-463, 2000.

ANGELO, C. L. Uma Leitura das Falas dos Alunos do Ensino Fundamental sobre a Aula de Matemática. 2012. 160 f. Tese (Doutorado em Educação Matemática) - Programa de Pós-Graduação em Educação Matemática, Instituto de Geociências e Ciências Exatas (IGCE), Unesp, Rio Claro, 2012. 
APPY, F.; APPY, B. L'efficacité par l'Enseignement Explicite. Article paru dans Résonances - Le mensuel de l'école valaisanne, v. 6, n. 3, p. 12-12, 2015.

BILLOUET, P. Débattre: Pratiques scolaires et démarches éducatives. Paris: L'Harmattan, 2007.

BIZZO, N. M. V.; CHASSOT, A. Ensino de Ciências: pontos e contrapontos. 1. ed. São Paulo: Summus Editorial, 2013. 190 p.

BRASIL. Parâmetros Curriculares Nacionais: Ensino Médio. Brasília: Ministério da Educação, 2000. 109p.

BRASIL. Resolução 466/2012. Diretrizes e normas regulamentadoras de pesquisas envolvendo seres humanos. Brasília: Ministério da Saúde/Conselho Nacional de Saúde, 2012.

CAILLOIS, R.; BARASH, M. Man, play, and games. Illinois: University Press, 1961.

CAILLOIS, R. Les jeux et les hommes. Le masque et le vertige. Paris: Editions Gallimard, 2015.

CAMOUS, H. Jouer avec les maths. Paris: Les Editions d'Organisation, 1985.

D'AGOSTINO, R. Transformation to normality of the null distribution of g1. Biometrika, v. 58, p. 679-681, 1970.

D'AGOSTINO, R.; PEARSON, E. Tests for departures from normality. Empirical results for the distribution of b1 and b2. Biometrika, v. 60, p. 613-622, 1973.

D'AGOSTINO, R. B.; BELANGER, A.; D'AGOSTINO JR., R. B. A suggestion for using powerful and informative tests of normality. American Statistician, v. 44, n. 4, p. 316$321,1990$.

D'AMBRÓSIO, U. Educação Matemática: da teoria à prática. São Paulo: Papirus Editora, 1996.

DEWEY, J. Experience \& Education. New York: Kappa Delta Pi, 1938.

DUVAL, R. Sémiosis et pensée humaine: Registres sémiotiques et apprentissage intellectuels. Suisse: Peter Lang, 1995.

ERAUT, M. Non formal learning and tacit knowledge in professional work. British journal of educational psychology, v. 70, n. 1, p. 113-136, 2000.

GANCHO, C. V. Como analisar narrativas. São Paulo: Ática, 1991.

GAUTHIER, C., TARDIF, M. La pédagogie. Théories et pratiques de l'Antiquité à nos jours. Montréal: Gaetan-Morin. 1996.

. et al. Pour une théorie de la pédagogie. Sainte-Foy: Université Laval, 1997. . et al. Enseignement Explicite et Réussite des Élèves. Montréal: Pearson, 2013. $322 \mathrm{p}$. 
KRASILCHIK, M. Prática de Ensino de Biologia. 4. ed. São Paulo: EDUSP, 2004. 197p.

LIKERT, R. A technique for the measurement of attitudes. Archives of Psychology, v. 22, p. 140-155, 1932.

MACHADO, N. J.; DAMBROSIO, U. Ensino de Matemática: pontos e contrapontos. 1. ed. São Paulo: Summus Editorial, 2014. v. 1. 176 p.

MENDES, A. C.; CARMO, J. dos S. Atribuições Dadas à Matemática e Ansiedade ante a Matemática: o relato de alguns estudantes do ensino fundamental. Bolema, v. 28, n. 50, p. 1368-1385, 2014.

MORIN, E. Introduction à la pensée complexe. Paris: Edition du Seuil, 1990.

MOYSÉS, L. Aplicações de Vygotsky à educação matemática. 9. ed. Campinas, SP: Papirus, 2009. $176 \mathrm{p}$.

MUNIZ, C. A. Brincar e jogar: enlaces teóricos e metodológicos no campo da educação matemática. Belo Horizonte: Autêntica, 2010. 145 p.

PIAGET, J. Epistemologia genética. 2. ed. São Paulo: Martins Fontes, 2002. 123 p.

SANTANA, O. A. Observação da Prática Docente: Um método para Licenciatura. Olinda: Livro Rápido, 2014. 50p.

. A. Evasão nas Licenciaturas das Universidades Federais: entre a apetência e a competência. Educação, v. 41, p. 311-327, $2016 a$.

. A. Fragmentação dos movimentos sociais nas universidades da América Latina: 1990-2015. Universidade e Sociedade, v. 57, n. 1, p. 36-45, $2016 \mathrm{~b}$.

.; IMAÑA-ENCINAS, J. Influência do vento no volume de toras e no fator de forma de Pinus caribaea var. hondurensis. Cerne, v. 19, p. 347-356, 2013.

SITZMANN, T. et al. Self-Assessment of Knowledge: A Cognitive Learning or Affective Measure? Academy of Management Learning \& Education, v. 9, n. 2, p. 169-191, 2010.

SOKAL, R. R.; ROHLF, F. J. Biometry: the principals and practice of statistics in biological research. New York: WH Freeman and Company, 1995.

VYGOTSKY, L. S. A formação social da mente: o desenvolvimento dos processos psicológicos superiores. 3. ed. São Paulo: Martins Fontes, 1989. 168 p.

VYGOTSKY, L. S. A construção do pensamento e da linguagem. São Paulo: Martins Fontes, $2001.496 \mathrm{p}$.

WINNICOTT, D. W. Jeu et réalité: I'espace potentiel. Paris: Gallimard, 1975.

ZAR, J. H. Biostatistical analysis. 4. ed. New Jersey: Prentice Hall, 1999. 123 p. 
Otacílıo Antunes Santana: Licenciado e Bacharel em Ciências Biológicas (Pontifícia Universidade Católica de Goiás), mestre e doutor em Ciências Florestais (Universidade de Braślia). Atualmente é Professor Adjunto na Universidade Federal de Pernambuco.

E-mail: otaciliosantana@gmail.com

Yekaterina Petrova: Graduada em Ciências Humanas e Sociais (Universidade Estatal de Moscou), doutora em Estudos Educacionais pela mesma instituição. Pesquisadora Associada da Universidade Estatal de Moscou.

E-mail: eka_petrova@bk.ru 
